\title{
Posttrial effects of presenting vs. omitting expected shock USs in the conditioned suppression procedure: Concurrent measurement of barpress suppression and freezing
}

\author{
JOHN J. B. AYRES and MICHAEL VIGORITO \\ University of Massachusetts, Amherst, Massachusetts
}

\begin{abstract}
Barpress suppression in a 1-min interval following CS trials was investigated using 16 rats in a conditioned suppression procedure with a two-stage design. For one group, each CS coterminated with a brief shock US in Stage 1; then, in Stage 2, only half the CSs ended with a shock, which in turn was followed 1 min later by a second shock. For a second group, the two stages were reversed. When CSs were followed by single shocks in Stage 1, posttrial suppression weakened across trials; but when, in Stage 2, double shocks followed half the CSs, posttrial suppression grew stronger. When half the trials were followed by double shocks in Stage 1, posttrial suppression was maintained at initial levels but weakened in Stage 2 when single shocks followed each trial. In both stages, posttrial suppression was stronger on nonreinforced than on reinforced trials. Two factors were hypothesized to control posttrial suppression. First, posttrial suppression weakens with training under the single-shock procedure because postshock temporal stimuli come to inhibit fear unless themselves paired with shock. Second, posttrial suppression is stronger on nonreinforced trials than on reinforced trials because freezing behaviors initiated during the CS are not disrupted by a US and so persist into the posttrial interval.
\end{abstract}

Investigators who use conditioned suppression procedures to study Pavlovian conditioning typically focus on the behavior of the subject during the presentation of the conditioned stimulus (CS). Much less attention has been paid to the behavior of the subject following CS termination. There are, of course, exceptions. For example, in their original demonstration of conditioned suppression of barpressing in rats, Estes and Skinner (1941) reported that when each CS trial terminated in the onset of a brief electric grid-shock unconditioned stimulus (US), the US initially disturbed or suppressed the rat's ongoing barpress behavior for a brief period following CS and US termination. However, this disturbance weakened with continued training. Other investigators (e.g., Ayres \& DeCosta, 1971 ; Lantz, 1973) have occasionally used post-CS suppression as a measure of conditioning to the CS. In these instances, a CS previously paired with a US was presented without a US, and considerable posttrial suppression was observed. It appears from the between-laboratory comparison just described that in

This research was supported by Grant BNS-8100322 from the National Science Foundation to John W. Moore and John J. B. Ayres. We are indebted to Michael Fanselow, who trained us in the use of the observational techniques described. We also wish to thank R. C. Bolles, Joan Bombace, Anthony Dickinson, Mike Fanselow, and John Moore for their comments on an earlier draft of the manuscript. The authors' address is: Department of Psychology, Middlesex House, University of Massachusetts, Amherst, MA 01003. the well trained rat posttrial suppression might be weaker following reinforced trials than following nonrein forced trials.

In recent unpublished work, we have confirmed this pattern of results. We found that when a noise CS was repeatedly paired with a shock US, suppression in a 1 -min period following each trial occurred at first but weakened significantly with training, thus confirming Estes and Skinner's observation. Then when the US was omitted on some trials but presented on others, suppression was greater following US omission than following US presentation, thus confirming the be tween-laboratory comparison just described. In addition, by using direct observational techniques to score freezing behavior (Bouton \& Bolles, 1980; Fanselow \& Bolles, 1979; Sigmundi, Bouton, \& Bolles, 1980), we determined that the rats froze significantly more following US omission than they did following US presentation. Moreover, it did not seem that the barpress suppression following US omission was caused by the rats' "searching" for the omitted shock. For example, we saw little or no grid sniffing that might suggest such a possibility.

Since barpress suppression and freezing have both long been regarded as indices of fear (e.g., Bouton \& Bolles, 1980; Davitz, Mason, Mowrer, \& Viek, 1957; Estes \& Skinner, 1941), it appeared that rats can be more frightened by the omission of an expected aversive event than by the presentation of one. One account of such a possibility might be as follows: When USs are 
widely spaced (ours had been spaced by at least $7 \mathrm{~min}$ ), the temporal cues that immediately follow them are explicitly unpaired with other USs and therefore gradually come to inhibit the fear conditioned to the context or "carried over" from the CS (Ayres, Mahoney, Proulx, \& Benedict, 1976; Davis \& McIntire, 1969; Davis, Memmott, \& Hurwitz, 1975; Moscovitch \& LoLordo, 1968). But when the US is omitted, these temporal cues by definition cannot be present and therefore cannot inhibit fear.

Although our unpublished observations were consistent with this account, they were also consistent with a slightly different account. This second account agrees that the weakening of posttrial suppression with training is due to the growth of inhibition conditioned to the posttrial temporal cues, but it holds that suppression following US omission reflects a continuation of freezing postures initiated during the CS and not broken up by the unconditioned activating effects of the US (Bolles \& Riley, 1973; Fanselow, 1982). Indeed, our observations revealed that there were often instances when a freezing posture initiated during the CS did persist past CS termination on trials on which the US was not presented. This observation is only suggestive, however, and it does not provide strong support for one account over the other. The following experiment was designed to do so.

If posttrial behavior can be understood in terms of the excitatory and inhibitory strengths of posttrial temporal stimuli, then it should be possible to alter posttrial behavior by manipulating the conditioned strengths of those stimuli. The present experiment performed such a manipulation in the following way. First, to provide a standard against which the effects of a manipulation could be assessed, one group received our usual conditioning procedure in which each CS trial coterminated with a single brief shock US. This group was expected to show a loss of posttrial barpress suppression across sessions like the loss described above. A second group received the same number of CS trials, but from the outset only half of them coterminated with shock. On these trials, moreover, a second shock was presented $1 \mathrm{~min}$ following the first. The purpose of giving this second shock was to maintain or enhance the initial excitatory strength of the temporal stimuli present in the first minute following each reinforced trial. If successful, this manipulation should prevent the decline of posttrial suppression across sessions and, indeed, might maintain or even enhance that initial suppression.

Because the US was omitted on half the trials for one group, posttrial suppression following US omission could once again be compared with that following US presentation. If more suppression occurred following US omission, then this result would extend the generality of our previous observation. However, such a result here might argue against the hypothesis that the suppression following US omission is due to the removal of inhibitory posttrial temporal stimuli; since the omitted shock here would be one often followed by a second shock, it is unlikely that the postshock temporal stimuli would become inhibitory.

\section{METHOD}

\section{Subjects}

The subjects were 16 male albino Holtzman rats, approximately 110 days old at the start of experimentation and housed individually in wire mesh cages in a continuously lighted room. Some of the rats had been deprived previously and trained to barpress for food pellets in an undergraduate laboratory. Others, part of the same stock, had not been trained. All rats were fed freely for at least 2 weeks prior to experimentation and were then reduced to $80 \%$ of their free-feeding weights before experimentation began.

\section{Apparatus}

Eight Gerbrands Skinner boxes were housed in ventilated $.61-\mathrm{m}$ cubes of $12.7-\mathrm{mm}$ plywood lined with acoustical tile. Any three of the wooden front doors of these cubes could be replaced by three portable doors constructed of two sheets of Plexiglas separated by a $6.5-\mathrm{cm}$-thick wooden frame. These portable Plexiglas doors permitted up to three rats to be observed directly and simultaneously under relatively soundproofed conditions. Mounted on the inside rear wall of each cube was a 7.5-W 110-V red light bulb; it was illuminated throughout the study to permit direct observation of the rats' freezing behavior. Mounted outside and above the cubes and out of the rats' line of sight was a small relay rack containing a relay, a Lehigh Valley Model 1356 indicator lamp panel, and two other 28-V red lamps; these devices all provided pacing stimuli (see procedure) designed to pace direct observations of freezing.

The inside dimensions of each Skinner box were $23.2 \times 20.3 \times$ $19.5 \mathrm{~cm}$. Each floor was composed of 18 stainless steel rods, $2 \mathrm{~mm}$ in diameter, mounted $1.3 \mathrm{~cm}$ apart center to center. The end walls were aluminum; the sides and top were transparent Plexiglas. Centered in one end wall was a standard Gerbrands bar, $1.5 \times 5.0 \mathrm{~cm}$, mounted $8 \mathrm{~cm}$ above the grid floor. In the lower left corner of this same wall was a $5.5 \times 5.0 \times 5.0 \mathrm{~cm}$ dipper receptacle.

On the lid of each Skinner box were two $10-\mathrm{cm}$ speakers. One provided an intermittent ( $1 \mathrm{sec}$ on, $.11 \mathrm{sec}$ off) white noise CS of approximately $80 \mathrm{~dB}$ intensity re $20 \mu \mathrm{N} / \mathrm{m}^{2}$; the other was not used. Scrambled grid shocks ( $1 \mathrm{~mA}$ for $1 \mathrm{sec}$ ) served as USs and were provided by eight Grason-Stadler shock sources (Models E1064GS and 700). Barpressing, the response to be suppressed by CS trials, was reinforced with 4-sec presentations of a $.1-\mathrm{ml}$ dipper cup containing a $32 \%$ (by weight) sucrose solution. Solid state programming apparatus and a paper tape reader were used to program both the Pavlovian and operant contingencies, and a computer was used to record data and to provide a pulse stream to pulse the pacing stimuli that paced the direct observations.

\section{Procedure}

Preliminary training. Preliminary barpress training began with three daily sessions of barpress shaping and ended with five daily $60-\mathrm{min}$ sessions in which responding was reinforced on a VI 1 -min schedule. This schedule remained in effect throughout the experiment. After preliminary training, the rats were assigned to two groups of eight, matched in terms of barpress rate during the last VI-training session and in terms of their prior history in the undergraduate laboratory.

Noise training. Stage 1 lasted for 9 days, during which Group S-D (single shock in Stage 1, double shock in Stage 2) received conditioning to a $2-\mathrm{min} 80-\mathrm{dB}$ noise $\mathrm{CS}$ while barpressing for sucrose on the VI 1-min schedule. Every CS coterminated with a 1-sec 1-mA scrambled grid shock US (single-shock procedure). Intervals between successive CS onsets were variable and 
ranged from 7 to $16 \mathrm{~min}$. Group D-S (double shock in Stage 1, single shock in Stage 2) received the same four daily CS presentations, but only half of these coterminated with the $1-\sec 1-\mathrm{mA}$ grid shock US. On these occasions, the US was followed $1 \mathrm{~min}$ later by a second $1-\sec 1-\mathrm{mA}$ shock (double-shock procedure). Trials 1 and 3 were reinforced on Days 1,5 , and 9; Trials 2 and 4 , on days 2 and 6; Trials 1 and 4, on Days 3 and 7; and Trials 2 and 3 , on Days 4 and 8 . The US was omitted on the remaining trials.

In Stage 2, immediately following Stage 1, the conditions were reversed for the two groups, and training continued for another 9 days. For Group S-D, Trials 2 and 4 were reinforced with double shocks on Days 1, 5, and 9; Trials 1 and 4, on Days 2 and 6; Trials 2 and 3, on Days 3 and 7; and Trials 1 and 3, on Days 4 and 8. Shock was omitted on the remaining trials. For Group D-S, every trial was reinforced by a single shock.

Direct observations. On the 1 st day of noise training, the Plexiglas doors were used in Boxes 1, 2, and 3; on the 2nd day, in Boxes 4, 5, and 6; and on the 3rd day in Boxes 7 and 8. On the 4 th day they were used again in Boxes 1, 2, and 3, etc. This rotation continued throughout the experiment. Direct observations were made on the last 3 days of each of the two stages of noise training. Thus, on Day 7 of Stage 1, the rats in Boxes 1, 2 , and 3 were directly observed; on Day 8 , the rats in Boxes 4, 5, and 6 ; and on Day 9, the rats in Boxes 7 and 8 . The same was true also in Stage 2. In summary, each rat was directly observed for one session toward the end of each stage, providing an estimate of each rat's "terminal freezing performance" in each stage. The procedure for scoring freezing was as follows. For $5 \mathrm{sec}$ prior to the start of each pre-CS, CS, and posttrial interval, six of the indicator lamps above the housing chambers lit up as a ready signal to the experimenters. At the termination of this signal, the experimenters scored the behavior of the first rat and then, paced by the relay clicks produced by the pulse stream (.5 sec on, $1.5 \mathrm{sec}$ off) from the computer, shifted their gaze to Rat 2 and then Rat 3 of each set of rats to be observed, scoring the behavior of each in turn. The two red pacing lamps above the housing chambers cycled on and off in such a way that evey third termination was a signal for scoring the behavior of Rat 1 . In this way, when the two experimenters worked together, both examined the same rat at the same time. The relay clicks and the flashing pacing lamps were always present throughout the session so that even if somehow detected by the rats, their presence in a pre-CS interval could not be a signal for CS presentations.

The pre-CS, CS, and posttrial periods were nominally $2 \mathrm{~min}$ long, as controlled by a paper-tape reader. The tape reader was not in perfect synchrony with the computer pulse stream that paced the experimenters, with the result that the experimenters always made 20 observations in each pre-CS, CS, and posttrial period for Rats 1 and 2 of each set of rats observed, but only 19 observations in each period for Rat 3 .

Each observation was scored as either "freezing" or "not freezing." "Freezing" was defined as the absence of any movement except for the movement of the rat's sides required for breathing. "Not freezing" was defined as any thing else. On some days, arbitrarily selected, Observer A performed the observations; on other days, Observer $\mathrm{V}$ did; and on some days, both did. The two observers agreed on $92 \%$ of the 2,268 observations they made together. Because Observer $\mathrm{V}$ made more observations than $\mathrm{Ob}$ server $A, V$ 's are reported below except when A's are the only ones available.

Treatment of data. Barpress suppression during all CSs was indexed in terms of the Annau and Kamin (1961) suppression ratio, $D /(D+B)$. Here $D$ denotes the number of responses during the $\mathrm{CS}$, and $\mathrm{B}$ denotes the number in a $2-\mathrm{min}$ period just before the CS. With this ratio, a score of zero denotes strong conditioned suppression, while a score of .5 suggests no effect. Suppression during a 1-min period following each trial was also measured and was quantified using the ratio $2 \mathrm{~A} /(\mathrm{B}+2 \mathrm{~A})$, where $A$ refers to the number of responses in the $1-\mathrm{min}$ period after a trial and B is as before. Whenever plots of suppression ratios rose across trials or sessions, "corrected" suppression ratios were computed. With these ratios, each rat's B score was always its pre-CS score from the first trial of the 1 st day of conditioning. This ratio guards against the possibility that plots of suppression ratios that rise with training could be artifacts of $B$ scores that fall with training (cf. Ayres, Berger-Gross, Kohler, Mahoney, \& Stone, 1979). Freezing was quantified in terms of the percent age of the observations in any pre-CS, CS, or posttrial interval to which a "freezing score" was assigned. High percentage scores therefore denote considerable freezing. In the posttrial interval, only freezing scores from the first minute were analyzed so that the measure of posttrial freezing and the measure of posttrial barpress suppression would be based on exactly the same period of time.

\section{RESULTS AND DISCUSSION ${ }^{1}$}

Conditioned suppression to the noise CS was acquired at similar rates in both groups in Stage 1. For Group S-D, the mean Annau-Kamin suppression ratio averaged over all CS trials was .11. For Group D-S, the mean suppression ratio averaged over all reinforced trials was .11 and over all nonreinforced trials was .10. In Stage 2, the results were similar. The mean suppression ratio averaged over all CS trials for Group D-S was .08. For Group S-D, the mean for all reinforced trials was .09 and for all nonreinforced trials was .07 .

Figure 1 shows the results of most interest, the barpress suppression in the 1 -min period that immediately followed each trial. Each data point is the mean of two reinforced or two nonreinforced trials. The corrected suppression ratio is plotted, and the B score that was used to compute all the ratios was the pre-CS rate on Trial 1 of Stage 1. (Plots of the data in terms of the usual Annau-Kamin ratio looked similar to the plots shown in Figure 1, and statistical analyses of those ratios supported the analyses of the corrected ratios described below.)

On Day 1 of Stage 1, Groups S-D and D-S showed comparable levels of posttrial suppression (compare $S$ curve with $D$ curve) following like-numbered reinforced trials $[T(8,8)=77, p>.10]$, but on Days 2 and 3 , Group D-S began showing more suppression and Group S-D began showing less. The greater amount of suppression in Group D-S is consistent with the idea that

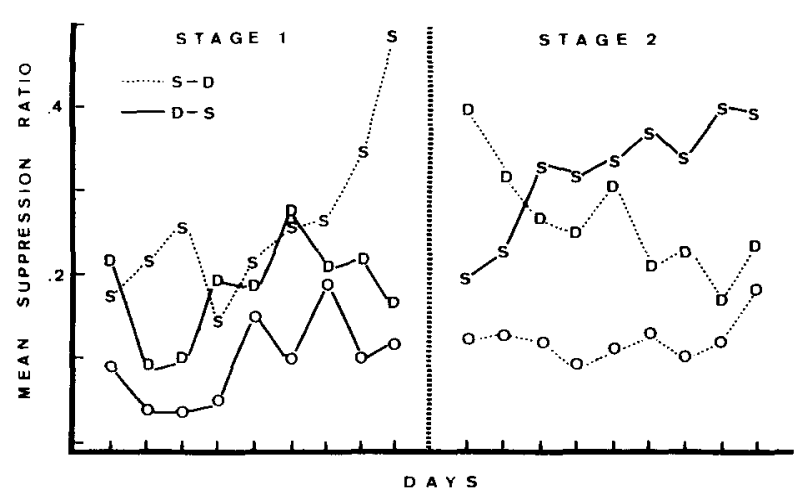

Figure 1. Barpress suppression in the 1-min posttrial period on shock-omission trials (O), double-shock trials (D), and singleshock trials (S). Each data point is the mean of two daily trials. 
the post-US temporal stimuli in this group, being themselves paired with a US, maintained excitatory strength. On Days 4, 5, and 6, however, differences did not emerge between the two groups, probably because of a programming error that was made on Day 3. On that day, Group S-D received its four shocks, but they were unsignaled by noise. Because of this error, that group's baseline barpress rate (see Table 1) was severely depressed, not so much on Day 3 but for several days thereafter, resulting in low corrected suppression ratios on those days. As the group's baseline rate began to recover, the differences in posttrial suppression seen early on reemerged. Suppression weakened for Group S-D (see $S$ curve) but was main tained for Group D-S (see D curve). By the last day of Stage 1, the two groups clearly differed on this measure $[T(8,8)=49, p=.05]$.

Throughout Stage 1, more suppression occurred following US omission (see O curve) than following US presentation (see $S$ curve or $D$ curve). When the results were averaged across all 9 days, Group D-S suppressed more following their nonreinforced trials than Group S-D did on like-numbered reinforced trials $[\mathrm{T}(8,8)=44.5$, $\mathrm{p}<.02]$. In addition, a within-group comparison indicated that Group D-S suppressed more following nonreinforced trials (see $O$ curve) than following reinforced trials (see D curve) $[\mathrm{T}(8)=0, \mathrm{p}=.01]$.

In Stage 2, the training conditions were reversed for the two groups, and the results changed accordingly. Group S-D now showed an increase in suppression in the 1-min posttrial period (see D curve), and Group D-S on like-numbered reinforced trials showed a decrease (see S curve). By the last day of Stage 2, the two groups clearly differed on this measure, with Group S-D showing significantly more suppression than Group D-S $[\mathrm{T}(8,8)=49, \mathrm{p}=.05]$ rather than nonsignificantly less suppression as had been the case on the 1st day of that stage $[\mathrm{T} 8,8)=77, \mathrm{p}>.05]$. Again in Stage 2, more suppression was seen following US omission (see $O$ curve) than following US presentation (see S curve or D curve), both according to between-group $[T(8,8)=93.5$, $\mathrm{p}<.01]$ and within-group $[\mathrm{T}(8)=0, \mathrm{p}=.01]$ comparisons.

Table 1

Mean Pre-CS Responding

\begin{tabular}{|c|c|c|c|c|c|c|c|c|c|}
\hline \multirow[b]{2}{*}{ Groups } & \multicolumn{9}{|c|}{ Days } \\
\hline & 1 & 2 & 3 & 4 & 5 & 6 & 7 & 8 & 9 \\
\hline \multicolumn{10}{|c|}{ Stage 1} \\
\hline S-D & 35 & 30 & 25 & 12 & 13 & 17 & 20 & 32 & 33 \\
\hline D-S & 22 & 22 & 18 & 23 & 24 & 26 & 29 & 30 & 28 \\
\hline \multicolumn{10}{|c|}{ Stage 2} \\
\hline S-D & 34 & 29 & 35 & 25 & 38 & 30 & 36 & 26 & 52 \\
\hline D-S & 32 & 37 & 36 & 34 & 38 & 33 & 35 & 33 & 39 \\
\hline
\end{tabular}

Note-Responses during each 2-min pre-CS period were averaged over the four trials of each session. The group means of those scores are presented in the table.
Direct observations of "terminal freezing performance" in each stage revealed posttrial freezing scores that were entirely consistent with the measures of barpress suppression. Thus, in Stage 1, Group D-S $(\bar{X}=27 \%)$ tended to freeze more on reinforced trials in the 1-min posttrial interval than did Group S-D $(\bar{X}=1 \%)$ on likenumbered reinforced trials $[\mathrm{T}(8,8)=85.5, \mathrm{p}=.065]$. Moreover, there was more freezing following US omission $(\bar{X}=45 \%)$ for Group D-S than there was following US presentation $(\bar{X}=27 \%)$ in the same group $[\mathrm{T}(8)=$ $1.5, \mathrm{p}<.05]$ or in Group S-D $(\overline{\mathrm{X}}=1 \%)[\mathrm{T}(8,8)=95$. $\mathrm{p}<.01]$. In Stage 2, these patterns of freezing reversed. Now Group S-D $(\bar{X}=26 \%)$ froze more after reinforced trials than did Group D-S $(\overline{\mathrm{X}}=1 \%)$ on like-numbered trials $[\mathrm{T}(8,8)=45, \mathrm{p}<.02]$. And there was more freezing following US omission $(\bar{X}=60 \%)$ for_Group $S-D$ than there was following US presentation $(\bar{X}=26 \%)$ in the same group $[\mathrm{T}(8)=2, \mathrm{p}<.05]$ or in Group D-S $(\bar{X}=2 \%)[T(8,8)=38, p<.01]$.

The finding that the double-shock procedure maintains barpress suppression in the 1 -min posttrial period is consistent with the hypothesis that posttrial behavior is influenced by the excitatory or inhibitory strengths of posttrial temporal stimuli, but it could also be a computational artifact of the corrected suppression ratio. If the double-shock procedure, for example, simply depressed the overall baseline rate relative to its level on Trial 1 of Stage 1, then the group getting double shocks would have low corrected suppression ratios, just as Group S-D did on Days 4, 5, and 6 of Stage 1. Table 1, which presents the groups' mean daily pre-CS rates does not support this possibility. When the pre-CS rates were averaged across all trials of each stage separately, the two groups did not differ in Stage $1[\mathrm{~T}(8,8)=69, \mathrm{p}>.10]$ or in Stage $2[T(8,8)=71, p>.10]$. Thus, the betweengroup differences in posttrial suppression are not due to differences in overall baseline rates. It therefore appears that the excitatory strength of posttrial temporal stimuli can be manipulated by pairing them with shock or by causing them to be explicitly unpaired with shock. Posttrial suppression is weak when the subject has been exposed to a schedule in which the posttrial temporal stimuli have been unpaired with shock but grows stronger if those stimuli are then paired with shock.

However, it does not appear that the barpress suppression that occurs following the omission of shock is due to the removal of inhibitory temporal stimuli. Even under the most ideal circumstances, many trials would probably be required for those stimuli to acquire inhibitory strength. Yet, even on Day 1 of Stage 1, there was more suppression following US omission than following US presentation. And, in the present experiment, the double-shock procedure was not ideal for conditioning inhibition to the post-US temporal stimuli, because those stimuli were paired with shock. The best interpretation, then, of the barpress suppression that occurs following US omission is probably that it reflects a carry- 
over of freezing postures initiated during the CS and undisrupted by the unconditioned activating effects of shock itself (Bolles \& Riley, 1973; Fanselow, 1982).

According to this interpretation, when the shock does occur on reinforced trials, it does not unconditionally activate barpressing; nor does barpressing occur primarily accidentally as an indirect result of other behaviors unconditionally activated by shock. The main effect of the shock is to break up freezing postures, if present, so that barpressing can be resumed.

Strengthening the above interpretation considerably is an unpublished observation that we previously made but until now have not described nor understood. Specifically, we found in earlier work that rats in our situation do not freeze as much to light CSs as they do to noise (cf. Sigmundi et al., 1980), even under otherwise comparable conditions; however, they do show comparable levels of barpress suppression during the light and noise. Because they freeze less during the light CS, freezing postures are less likely to be maintained into the posttrial interval when the US is omitted. To the extent that maintained freezing postures account for posttrial barpress suppression, there should be less postlight suppression than postnoise suppression, even though suppression during these stimuli is similar. And, because there is little postlight freezing after US-omission trials, the effects of US omission vs. presentation on both freezing and barpress suppression should be less dramatic following light CSs than following noise CSs. Our unpublished observations were entirely consistent with these expectations.

It is also possible to adduce further support for the above interpretation using the present data. If posttrial barpress suppression is due to maintained freezing postures, then freezing scores during the CS should correlate with both posttrial freezing scores and posttrial suppression scores, at least on nonreinforced trials. On reinforced trials, however, freezing initiated during the CS should be disrupted by US presentation; and therefore freezing during the CS should be poorly correlated with both posttrial freezing and suppression. To test these predictions, we examined first the "terminal freezing performance scores" that were obtained on nonreinforced trials of Stage 1 for Group D-S and Stage 2 for Group S-D. On the first of these two trials, the Pearson correlation between CS-freezing and posttrial freezing was .62, and between CS-freezing scores and posttrial suppression ratios, it was -.67 (ps $<.01) .^{2}$ On the second of these trials, the same correlations were, respectively, .71 and $-.80(\mathrm{ps}<.002)$. Next we examined the terminal freezing performance scores on reinforced trials of Stage 1 for Group D-S and Stage 2 for Group S-D. When these scores were correlated with posttrial freezing and posttrial barpress suppression scores obtained on the same trials, the correlations ranged from -.32 to .52 and only the highest (that between CS freezing and posttrial freezing on the first of the two trials) was reliable $(p<.05)$. Finally, to the extent that posttrial barpress suppression is due to posttrial freezing, these two measures should also be correlated. And, indeed, on the two nonreinforced trials available for analysis, the correlations were -.80 and -.74 (ps $<.002)$. On the two reinforced trials, the correlations were $-.45(\mathrm{p}>.05)$ and $-.64(\mathrm{p}<.01)$. Thus, these data clearly indicate that posttrial suppression is correlated with both $\mathrm{CS}$ freezing and posttrial freezing, especially on nonreinforced trials.

Taken together, the various results of this study suggest that two factors control posttrial barpress suppression. First, posttrial suppression weakens with training under the usual single-shock procedure because postshock temporal stimuli become inhibitory unless they themsleves are paired with shock. This inhibition weakens the fear conditioned to contextual cues or carried over from the CS. Second, posttrial suppression is stronger on nonreinforced trials than on reinforced trials because freezing behaviors initiated during the CS are not disrupted by a US on nonreinforced trials and therefore persist into the posttrial interval. These behaviors prevent the resumption of barpressing.

The continuation of barpress suppression and freezing beyond CS termination has several potentially important theoretical implications. For example, it is not at all what we might expect on the basis of an opponentprocess theory (Solomon \& Corbit, 1974). Within that theory, CSs paired with shock are expected to gain control over conditioned A states. But the A states automatically engage an opponent $b$ process that takes a relatively long time to decay. When the CS terminates and is nonreinforced, only the opponent B state should remain, and it should decay slowly back to baseline (see discussion by Solomon \& Corbit, 1974, of data by Rescorla \& LoLordo, 1965). Our observations, however, reveal no suggestion of a B state in the 1-min posttrial interval. The rat appears to be frightened after a nonreinforced CS terminates, just as it was frightened during the CS itself. Our data also seem inconsistent with a conditioned opponent-process theory (Schull, 1979). According to that view, CSs come to control conditioned opponent (b) processes precisely timed to occur at the moment of US occurrence. These processes oppose those (a processes) elicited unconditionally by the US itself. If the US is omitted on a trial, only the opposing b process can be manifest in behavior. It seems reasonable that the unconditioned a processes elicited by shock might manifest themselves in symptoms of fear. But we find those symptoms exactly when the opposing b processes should suffer the least competition from the unconditioned a processes.

Lastly, we might suggest that the possibility that fear and freezing persist beyond CS termination on nonreinforced trials may be relevant to some other recent findings on the effects of US omission in Pavlovian conditioning. For example, Dickinson, Hall, and Mackintosh (1976) reported that omitting an expected US in the compound conditioning stage of the Kamin blocking 
procedure alleviated blocking to the target element (i.e., enhanced conditioning). Similarly, Cheatle and Rudy (1978) reported that if a neutral stimulus, $X$, was compounded with a preconditioned stimulus, A, X would gain second-order conditioned strength only if the US used to precondition A did not follow the AX compound. And Hall and Pearce (1982) reported that "associability" could be restored to a CS that had lost it through repeated pairings with a weak US by omitting the US on one or two trials before pairing the CS with a stronger US in the next stage. Perhaps these phenomena are related in that all involve the pairing of a CS with an emotional state in the posttrial period, a state that, when USs are widely spaced, is more likely following US omission than following US presentation. Alternatively, perhaps the animal is especially alert during this emotional state. Recent evidence, for example, suggests a heightened state of alertness during freezing behavior (e.g., see Hollis, 1982). Perhaps this heightened alertness enables the animal to process better the events of the preceding trial or makes it attend more to those events the next time they occur. The latter idea seems quite similar to the Hall and Pearce (1982) concept of restored associability or salience.

\section{REFERENCES}

Annau, Z., \& Kamin, L. J. (1961). The conditioned emotional response as a function of intensity of the US. Journal of Comparative and Physiological Psychology, 54, 428-432.

Ayres, J. J. B., Berger-Gross, P., Kohler, E. A., Mahoney, W. J., \& Stone, S. (1979). Some orderly nonmonotonicities in the trial-by-trial acquisition of conditioned suppression: Inhibition with reinforcement? Animal Learning \& Behavior, 7, 174-180.

Ayres, J. J. B., \& DeCosta, M. J. (1971). The truly random control as an extinction procedure. Psychonomic Science, 24, 31-33.

Ayres, J. J. B., Mahoney, W. J., Proulx, D. T., \& Benedict, J. O. (1976). Backward conditioning as an extinction procedure. Learning and Motivation, 7, 368-381.

Bolles, R. C., \& Riley, A. (1973). Freezing as an avoidance response: Another look at the operant-respondent distinction. Learning and Motivation, 4, 268-275.

Bouton, M. E., \& Bolles, R. C. (1980). Conditioned fear assessed by freezing and by the suppression of three different baselines. Animal Learning \& Behavior, 8, 429-434.

Cheatle, M. D., \& Rudy, J. W. (1978). Analysis of second-order odor-aversion conditioning in neonatal rats: Implications for Kamin's blocking effect. Journal of Experimental Psychology: Animal Behavior Processes, 4, 237.249.

Davis, H., \& McIntire, R. W. (1969). Conditioned suppression under positive, negative, and no contingency between conditioned and unconditioned stimuli. Journal of the Experimental Analysis of Behavior, 12, 633-640.
Davis, H., Memmott, J., \& Hurwitz, H. M. B. (1975). Autocontingencies: A model for subtle behavioral control. Journal of Experimental Psychology: General, 104, 169-188.

Davitz, J. R., Mason, D. J., Mowrer, O. H., \& Viek, P. (1957). Conditioning of fear: A function of the delay of reinforcement. American Journal of Psychology, 70, 69-74.

Dickinson, A., Hall, G., \& Mackintosh, N. J. (1976). Surprise and the attenuation of blocking. Journal of Experimental Psychology: Animal Behavior Processes, 2, 313-322.

Estes, W. K., \& Skinne R, B. F. (1941). Some quantitative properties of anxiety. Journal of Experimental Psychology, 29, $390-400$.

Fanselow, M. S. (1982). The postshock activity burst. Animal Learning \& Behavior, 10, 448-454.

Fanselow, M. S., \& Bolles, R. C. (1979). Triggering of the endorphin analgesic reaction by a cue previously associated with shock: Reversal by naloxone. Bulletin of the Psychonomic Society, 14, 88-90.

HALL, G., \& PeArce, J. M. (1982). Restoring the associability of a pre-exposed CS by a surprising event. Quarterly Journal of Experimental Psychology, 34B, 127-140.

Hollande R, M., \& Wolfe, D. A. (1973). Nonparametric statistical methods. New York: Wiley.

Holl1s, K. L. (1982). Pavlovian conditioning of signal-centered action patterns and autonomic behavior: $A$ biological analysis of function. Advances in the Study of Behavior, 12, 1-64.

LANTz, A. E. (1973). Effect of number of trials, interstimulus interval, and dishabituation on subsequent conditioning in a CER paradigm. Animal Learning \& Behavior, 1, 273-277.

Moscovitch, A., \& LoLondo, V. M. (1968). Role of safety in the Pavlovian backward fear conditioning procedure. Journal of Comparative and Physiological Psychology, 66, 673-678.

Resconla, R. A., \& LoLordo, V. M. (1965). Inhibition of avoidance behavior. Journal of Comparative and Physiological Psychology, 59, 406-412.

Schult, J. (1979). A conditioned opponent theory of Pavlovian conditioning and habituation. In G. H. Bower (Ed.), The psychology of learning and motivation (Vol. 13). New York: Academic Press.

Sigmundi, R. A., Bouton, M. E., \& Bolles, R. C. (1980). Conditioned freezing in the rat as a function of shock intensity and CS modality. Bulletin of the Psychonomic Society, 15, 254-256.

Solomon, R. L., \& Corbit, J. D. (1974). An opponent-process theory of motivation: I. Temporal dynamics of affect. Psychological Review, 81, 119-145.

\section{NOTES}

1. Between-group contrasts were made using Wilcoxon rank sums tests, and within-group contrasts were made using Wilcoxon signed ranks tests (e.g., Hollander \& Wolfe, 1973). All p values are two-tailed.

2. The correlation between freezing and suppression is negative because high freezing scores denote strong freezing but high suppression ratios denote weak suppression.

(Manuscript received June 17, 1983; revision accepted for publication October $7,1983$. 